\title{
ESTADO NUTRICIONAL, VIGOR E PRODUÇÃO EM VIDEIRAS CULTIVADAS COM PLANTAS DE COBERTURA ${ }^{1}$
}

\author{
JOVANI ZALAMENA ${ }^{2}$, PAULO CEZAR CASSOL ${ }^{3}$, GUSTAVO BRUNETTO ${ }^{4}$, \\ MARCO ANDRÉ GROHSKOPF ${ }^{5}$, MARIA SUELI HEBERLE MAFRA $^{6}$
}

\begin{abstract}
RESUMO - Espécies perenes ou anuais de plantas de cobertura podem ser cultivadas em vinhedos para proteger a superfície do solo e também controlar a disponibilidade de água e nutrientes à videira. $\mathrm{O}$ trabalho objetivou avaliar o estado nutricional, o vigor e a produção de uva em videiras consorciadas com espécies anuais e perenes de plantas de cobertura submetidas a dois manejos. O experimento foi conduzido nas safras de 2009/2010 e 2010/2011, em vinhedo da cultivar Cabernet Sauvignon, em São Joaquim (SC), sobre um Cambissolo Húmico Distrófico. Os tratamentos foram: testemunha, caracterizado pela presença de plantas espontâneas controladas por dessecação na linha e por roçadas nas entrelinhas; a espécie perene de planta de cobertura, festuca (Festuca arundinacea); duas sucessões de espécies anuais, azevém-moha (Lolium multiflorum-Setaria italica) e aveia-branca trigo-mourisco (Avena sativa-Fagopyrum esculentum); e dois tipos de manejo das plantas, com e sem transferência do resíduo produzido na linha para a entrelinha das videiras. Foram coletadas folhas completas no pleno florescimento e na mudança da cor das bagas para análise dos teores totais de N, P, K, Ca e Mg. Determinaram-se o comprimento dos ramos e de seus entrenós, a massa dos ramos podados e calculou-se o índice de Ravaz. Na colheita, foram determinados o comprimento, largura e massa de cachos, a produção de uva por planta e a massa de 100 bagas. As videiras consorciadas com espécies de plantas de cobertura anuais apresentaram maior teor de $\mathrm{N}$ total nas folhas na floração, maior vigor e produção de uva. O manejo das plantas de cobertura, mediante transferência dos resíduos culturais da linha de videiras para a entrelinha, não afetou o vigor da videira nem a produção de uva, mas diminuiu o teor total de $\mathrm{N}$ nas folhas, na fase da floração. $\mathrm{O}$ cultivo da festuca como cobertura do solo do vinhedo pode ser uma alternativa eficaz para se diminuir o vigor da videira.
\end{abstract}

Termos para indexação: Adubo verde, nutrição mineral, crescimento vegetativo, componentes de produção, Vitis vinifera.

\section{NUTRITIONAL STATUS, VIGOR AND YIELD OF GRAPEVINES INTERCROPPED WITH COVER CROPS}

\begin{abstract}
Perennial or annual species of cover crops can be grown in vineyards to protect the soil surface and to reduce the availability of water and nutrients to the vine. The study aimed to evaluate the nutritional status, vigour and yield of grapevines intercropped with some species of cover crops under two different managements. A field experiment was conducted for two years, 2009 through 2011, in a vineyard of cv Cabernet Sauvignon in a Haplumbrept soil. The following treatments were evaluated: a control, where weeds were controlled by chemical drying in the grapevine row and by mowing in the inter row; a perennial species, tall fescue (Festuca arundinacea); two sequences of annual species, ryegrass-moha (Lolium multiflorum-Setaria italica) and oat-buckwheat (Avena sativa-Fagopyrum esculentum); and two types of crop residues management, with and without its transfer of the grapevine row to the inter row. The grapevine leaves were sampled at flowering and at berries softening stages for analysis of N, P, K, Ca and $\mathrm{Mg}$ contents. It was determined the branches and internodes lengths, branches pruned mass, grape bunches length, width and mass, yield per plant and the weight of 100 berries and it was also calculated the Ravaz index of the grapevines. Grapevines intercropped with succession of annual cover crops showed higher total $\mathrm{N}$ content in leaves at flowering, vigour and grape yield. The transfer of the crop residue from the row to the inter row, did not affect the grapevine vigour and yield, but decreased the total content of $\mathrm{N}$ in the leaves at flowering. The tall fescue as soil cover crop in vineyard can be an effective alternative to reduce the vigor of the grapevine.
\end{abstract}

Index terms: Green manure, mineral nutrition, green cover, yield components, Vitis vinifera.

\footnotetext{
'(Trabalho 012-13).Recebido em: 03-01-2013. Aceito para publicação em: 28-10-2013. Parte da Tese de doutorado do primeiro autor. Trabalho realizado com recursos da FAPESC.

${ }^{2}$ Eng. Agr., Doutor em Manejo do Solo, Pós doutorando no Programa de Pós Graduação em Ciência do Solo/UFSM. E-mail: jovanizalamena@yahoo.com.br

${ }^{3}$ Eng. Agr., Dr, Prof. Associado do Programa de P.G. em Ciência do Solo-CAV/UDESC. Lages - SC. E-mail: a2pc@cav.udesc.br.

${ }^{4}$ Eng. Agr., Doutor em Ciência do Solo, Prof. do Depto de Solos e do Programa de Pós-Graduação em Ciência do Solo/ UFSM. Centro de Ciências Rurais (CCR), Santa Maria-RS. E-mail: brunetto.gustavo@gmail.com

${ }^{5}$ Eng. Agr, Mestre do PPG em Ciência do Solo- CAV/UDESC. E-mail: marco-a06g@hotmail.com.

${ }^{6}$ Eng. Agr, Doutora do PPG em Ciência do Solo- CAV/UDESC. E-mail: mshmafra@gmail.com.
} 


\section{INTRODUÇÃO}

Os solos predominantes na região do Planalto Catarinense, em geral, possuem alto teor de matéria orgânica e elevada acidez potencial. A partir da década de 90, parte desses solos sob campo natural passou a ser incorporada ao sistema de produção de uva. Para a implantação dos vinhedos, tais solos foram submetidos à aplicação de calcário para a correção da acidez do solo. Porém, com o aumento do valor de $\mathrm{pH}$, ocorre maior atividade microbiana, o que aumenta a mineralização da matéria orgânica do solo e, por consequência, a disponibilidade de nutrientes, especialmente de nitrogênio $(\mathrm{N})$. Com isso, pode acontecer incremento do teor de $\mathrm{N}$ total nas folhas das videiras (BRUNETTO et al., 2007; MAFRA et al., 2011; BRUNETTO et al., 2012) e crescimento vegetativo excessivo. Assim, esperase menor incidência de luz no interior do dossel, favorecendo o aparecimento de doenças fúngicas e diminuindo o número de flores fecundadas, o que resulta em menor número de bagas por cacho, retarda a senescência das folhas e o processo de dormência dos ramos, e afeta negativamente a composição da uva e de seu mosto (KELLER et al., 1999; DUCHÊNE et al., 2001; BRUNETTO et al., 2008).

Espécies de plantas de cobertura anuais em sucessão, como a aveia (Avena sativa), o centeio (Secale cereale) e o azevém (Lolium multiflorum), entre outras ou até mesmo espécies de plantas de cobertura perenes, entre elas a festuca (Festuca arundinacea) são cultivadas nas linhas e entrelinhas dos vinhedos, especialmente para proteger a superfície do solo contra o impacto da gota da chuva o que, por consequência, pode diminuir as perdas de solo por erosão (SCIENZA et al., 1988; VALENTI et al., 1999; COLUGNATI et al., 2003). No entanto, em solos com elevados teores de matéria orgânica, o que lhes confere alta disponibilidade de $\mathrm{N}$, as espécies anuais e, especialmente, perenes de plantas de cobertura também podem ser cultivadas em vinhedos para diminuir a disponibilidade de água e nutrientes no solo (WHEELER et al., 2005; LOPES et al., 2008; LOPES et al., 2011). Com isso, as videiras podem apresentar estado nutricional mais adequado ao seu desenvolvimento, estimado pelo teor total de nutrientes nas folhas; menor vigor da parte aérea que pode ser caracterizado pela massa dos ramos podados, comprimentos de ramos e entrenós e Índice de Ravaz; e, ainda, produções de uva adequadas e que possuam composição química desejada à vinificação (WHEELER et al., 2005; CELETTE et al., 2005; CELETTE et al., 2009; ZALAMENA et al., 2013).

Somado a isso, a roçada da parte aérea das plantas de cobertura anuais ou perenes, localizadas na linha de plantio, onde normalmente é encontrada a maior quantidade de raízes das videiras, com transferência de seus resíduos para a entrelinha, onde as raízes da cultura principal ocorrem em menor quantidade, também pode ser uma alternativa adicional para reduzir a disponibilidade de nutrientes à videira, mesmo que esta cultura normalmente absorva pequenas quantidades de nutrientes derivados de resíduos de plantas de cobertura em decomposição na superfície do solo (BRUNETTO et al., 2011). O trabalho objetivou avaliar o estado nutricional, o vigor e a produção de uva em videiras consorciadas com espécies de plantas de cobertura do solo, submetidas a diferentes manejos.

\section{MATERIAL E MÉTODOS}

O trabalho foi realizado em um vinhedo comercial no município de São Joaquim (SC), região do Planalto Sul Catarinense (latitude $28^{\circ} 14^{\prime} 10^{\prime \prime}$ $\mathrm{S}$, longitude $50^{\circ} 4^{\prime} 15^{\prime \prime} \mathrm{W}$, altitude $1.129 \mathrm{~m}$ ), nas safras de 2009/2010 e 2010/2011. O vinhedo foi implantado em 2002, com a cultivar Cabernet Sauvignon enxertada sobre o porta-enxerto Paulsen 1103, na densidade de 2.870 plantas por hectare $(1,2 \times 2,9 \mathrm{~m})$ e conduzido em sistema espaldeira. O clima da região, segundo a classificação Köppen, é $\mathrm{Cfb}$, mesotérmico úmido com verões amenos e precipitação média anual de $1.903 \mathrm{~mm}$, sendo julho o mês mais frio, com temperaturas mínimas e máximas médias de $6,2^{\circ} \mathrm{C}$ e $14,9^{\circ} \mathrm{C}$, e fevereiro o mês mais quente, com temperaturas mínimas e máximas médias de $13,6^{\circ} \mathrm{C}$ e $22,6^{\circ} \mathrm{C}$, respectivamente. A precipitação pluviométrica acumulada ao longo das fases vegetativa e produtiva da videira, no período estival de dezembro até metade de abril, quando foi realizada a colheita, totalizou 1.025 e $947 \mathrm{~mm}$ nas safras de 2009/2010 e 2010/2011, respectivamente, conforme dados cedidos gentilmente pela EPAGRICIRAN. O solo é um Cambissolo Húmico Distrófico e apresentava, na camada de $0-10 \mathrm{~cm}$, no momento da instalação do experimento, os seguintes atributos: 481; 367 e $152 \mathrm{~g} \mathrm{~kg}^{-1}$ de argila, silte e areia, respectivamente, determinados pelo método da pipeta (EMBRAPA, 1997); $81 \mathrm{~g} \mathrm{~kg}^{-1}$ de matéria orgânica (TEDESCO et al., 1995); pH em água 6,8 (relação 1:1); teores de $\mathrm{Ca}, \mathrm{Mg}$ e $\mathrm{Al}$ trocáveis (extrator de $\mathrm{KCl} 1 \mathrm{~mol} \mathrm{~L}^{-1}$ ) de 12,0, 5,0 e 0,0 $\mathrm{cmol}_{\mathrm{c}} \mathrm{dm}^{-3}$, respectivamente, e teores de $\mathrm{P}$ e $\mathrm{K}$ extraíveis (extrator de Mehlich 1) de 6,8 e $436 \mathrm{mg} \mathrm{dm}^{-3}$, respectivamente.

Os tratamentos foram: testemunha, duas sucessões de espécies anuais de plantas de coberturas, uma espécie perene e dois tipos de manejos, sendo 
assim denominados: T1- testemunha, caracterizada pela presença de plantas espontâneas controladas com dessecamento por herbicida (glifosato), na faixa da linha (L) (largura de 1,10 m) e por roçadas nas entrelinhas (EL) (largura de 1,80 m); T2- a sucessão das plantas anuais moha (Setaria itálica) e azevém (Lolium multiflorum) roçadas com o resíduo cultural (RC) distribuído uniformemente sobre a área cultivada; T3- a sucessão das plantas anuais moha e azevém roçadas com transferência do RC da L para a EL; T4- a sucessão das plantas anuais trigo-mourisco (Fagopyrum esculentum) e aveia-branca (Avena sativa) roçadas com o RC distribuído uniformemente sobre a área cultivada; T5- a sucessão das plantas anuais trigo-mourisco e aveia-branca roçadas com transferência do RC da L para a EL; T6- a espécie perene festuca (Festuca arundinacea) roçada com o RC distribuído sobre a área cultivada, e T7- a festuca roçada com transferência do RC da L para a EL. O tratamentotestemunha representou a condição de manejo normalmente encontrada nos vinhedos da região.

$\mathrm{O}$ experimento foi instalado em janeiro de 2009, quando foram semeados o primeiro ciclo das espécies anuais de verão e a espécie perene. A partir daí, as espécies foram cultivadas seguindo o ciclo anual, moha e trigo-mourisco no verão, e aveia-branca e azevém no inverno. As densidades de semeadura de aveia-branca, azevém, moha, trigomourisco e festuca foram $80 ; 20 ; 7 ; 50$ e $10 \mathrm{~kg} \mathrm{ha}^{-1}$ de semente, respectivamente, valores ajustados para $100 \%$ de poder germinativo. A semeadura na linha de plantio das videiras foi realizada com semeadora manual, tipo saraquá, enquanto na entrelinha usou-se uma semeadora mecanizada. A roçada e o manejo das plantas foram realizados no início da diferenciação floral das plantas anuais, o que proporcionou rebrotes e novos cortes adicionais durante os ciclos de cultivo, totalizando, até o final do período de avaliação, sete cortes em cada sucessão de plantas anuais e nove cortes na espécie perene. A área útil das parcelas compreendeu duas filas de seis plantas de videira, mantendo-se duas plantas nas cabeceiras e uma fila em cada lado como bordadura. $\mathrm{O}$ delineamento experimental foi o de blocos ao acaso, com quatro repetições.

Amostras de duas folhas completas (limbo + pecíolo) por videira foram coletadas no pleno florescimento e na mudança de cor das bagas. As folhas foram secas em estufa com circulação de ar forçado, com temperatura média de $65^{\circ} \mathrm{C}$, moídas e preparadas para análises dos teores totais de $\mathrm{N}, \mathrm{P}$, K, Ca e Mg (TEDESCO et al., 1995). A colheita de uva foi realizada no estágio de plena maturação, em meados de abril de cada ano, mensurando-se o número e a massa total de cachos por parcela. Coletou-se aleatoriamente um cacho em ambos os lados de cada planta, determinando-se a massa em balança digital e as dimensões de comprimento e largura com paquímetro. Destes cachos, foram coletadas 100 bagas, na parte inferior, mediana e superior (BRUNETTO et al., 2008) e mensurou-se sua massa. A avaliação de comprimento de ramo e de seus entrenós foi realizada na safra de 2010/2011, no mês de maio, quando em cada planta foram selecionados dois ramos do ano, medindo-se o comprimento total, com fita métrica, e contando-se o número de nós. A massa seca dos ramos foi estimada através do somatório do material das podas verdes realizadas durante o ciclo vegetativo, e da poda seca, realizada no início do ciclo seguinte. $\mathrm{O}$ índice de Ravaz foi obtido pela razão entre massa de frutos/ massa de ramos (CUS, 2004). Durante a condução do experimento, as videiras não receberam nenhuma adubação nitrogenada, mas foram adubadas com $46 \mathrm{~kg} \mathrm{ha}^{-1}$ de $\mathrm{K}_{2} \mathrm{O}$ em 2009 e com 42 e $52 \mathrm{~kg} \mathrm{ha}^{-1}$ de $\mathrm{P}_{2} \mathrm{O}_{5}$ em 2010 e 2011, respectivamente (CQFS$\mathrm{RS} / \mathrm{SC}$, 2004). Estes adubos foram distribuídos a lanço na superfície do solo, na faixa da linha das videiras, sem incorporação, no mês de agosto. Em cada safra, foram realizadas cerca de 12 aplicações de fungicidas, seguindo a recomendação técnica proposta para a cultura, e no mês de setembro, foi realizada a poda de inverno, enquanto em janeiro, a poda verde, caracterizada pela retirada de brotações laterais e pelo desponte dos ramos. Os ramos destas duas podas foram secos em estufa com ventilação forçada à temperatura média de $65^{\circ} \mathrm{C}$, determinandose a produção de matéria seca.

A análise estatística dos dados foi feita comparando-se os tratamentos através de quatro contrastes ortogonais, conforme segue: contraste C1 - testemunha (T1) versus plantas de cobertura anuais (T2 a T5); contraste C2- testemunha (T1) versus planta perene (T6 e T7); contraste C3-plantas anuais (T2 a T5) versus planta perene (T6 e T7); e o contraste $\mathrm{C} 4$ que compara os dois manejos das plantas de cobertura (T2, T4 e T6 versus T3, T5 e T7).

\section{RESULTADOS E DISCUSSÃO}

\section{Estado nutricional das videiras}

Na safra de 2009/2010, as sucessões de plantas anuais de cobertura, azevém-moha e aveiabranca trigo-mourisco, e a perene festuca, cultivadas em consórcio com a videira, não influenciaram o 
teor de $\mathrm{N}$ total das folhas no pleno florescimento e na mudança da cor das bagas, comparativamente ao tratamento-testemunha (Tabela 1). No entanto, no florescimento da safra de 2010/2011, as videiras cultivadas em consórcio com as sucessões de plantas anuais de cobertura apresentaram teor de $\mathrm{N}$ total nas folhas maior que o observado nos tratamentostestemunha e consórcio com a perene festuca. Esta diferença entre as plantas anuais e a perene ocorreu porque a última mostrou maior capacidade competitiva, mantendo-se em crescimento por mais tempo ao longo do ciclo da videira, e durante todo o período acumulou maior quantidade de matéria seca, 10,0 t ha- ${ }^{-1}$, contra $6,1 \mathrm{t} \mathrm{ha}^{-1}$ das plantas em sucessão anuais (ZALAMENA, 2012). Isto, provavelmente, implicou maiores demandas de água e nutrientes do solo, fazendo com que as videiras absorvessem menores quantidades de $\mathrm{N}$ da solução do solo (CELETTE et al., 2009). Além disso, a relação C:N da festuca foi maior $(\mathrm{C}: \mathrm{N}=10,5)$ do que as médias das plantas que compõem a sucessão de espécies anuais $(C: N=6,1)$, podendo, desta forma, durante a decomposição das plantas, a espécie perene festuca ter adicionado menos $\mathrm{N}$ ao solo e,consequentemente, para a videira.

A decomposição dos resíduos das plantas anuais na superfície do solo pode incrementar a disponibilidade de nutrientes, favorecendo a absorção pela videira, especialmente do nitrato $\left(\mathrm{N}^{-\mathrm{NO}_{3}}{ }^{-}\right)$, que é a forma de $\mathrm{N}$ absorvida em maior quantidade pelas raízes finas da videira, que, no florescimento, normalmente, apresentam rápido crescimento (EISSENSTAT, 2007). Na ressemeadura das plantas anuais, houve certo revolvimento em parte da camada superficial do solo, o que também pode ter favorecido a decomposição dos resíduos das plantas, associado com a menor relação $\mathrm{C}: \mathrm{N}$, com o consequente aumento na disponibilidade de N. No entanto, a videira geralmente absorve e acumula,em seus órgãos perenes e anuais, quantidades relativamente pequenas do $\mathrm{N}$ derivado da decomposição de resíduos de plantas de cobertura depositados na superfície do solo (BRUNETTO et al., 2011). Ao longo do ciclo anual da videira, as plantas de cobertura do solo também absorvem água e nutrientes da solução do solo, especialmente o $\mathrm{N}$, o que pode até mesmo diminuir a disponibilidade deste elemento à cultura (CELETTE et al., 2009). Assim, normalmente, não se espera aumento do teor de $\mathrm{N}$ total nas folhas das videiras consorciadas com plantas de cobertura anuais, podendo até ocorrer o inverso, como observado por Wheeler et al. (2005), que constataram menores teores de $\mathrm{N}$ total e de $\mathrm{N}-\mathrm{NO}_{3}{ }_{3}^{-}$no pecíolo das folhas de videiras da cultivar Cabernet Sauvignon, em consórcio com chicória (Cichorium endivia), nas linhas e entrelinhas de plantio, comparativamente àquelas do tratamento-testemunha, com plantas espontâneas.

O manejo das plantas de cobertura com a roçada e a transferência dos resíduos culturais da linha para a entrelinha das videiras diminuiu o teor de $\mathrm{N}$ total nas folhas coletadas no pleno florescimento, nas duas safras avaliadas (Tabela 1). Essa diminuição ocorreu devido à supressão da ciclagem do nutriente que seria liberado da decomposição dos resíduos culturais na superfície do solo que, provavelmente, ocorreu onde não houve a transferência, concentrando-se justamente no período que antecede o pleno florescimento da videira. Isso indica que o cultivo de plantas de cobertura na faixa da linha de plantio da videira manejadas com remoção de seus resíduos culturais pode, no período imediato ao da decomposição destes, resultar em menor disponibilidade de $\mathrm{N}$ no solo, na área em que se encontra a maior quantidade de raízes finas, que são responsáveis pela maior parte da absorção de água e nutrientes (SOARES; NASCIMENTO, 1998). Quando as folhas das videiras foram coletadas na mudança da cor das bagas, não houve diferença em seu teor de $\mathrm{N}$ por causa do tipo de manejo nas duas safras avaliadas. Em parte, isso pode evidenciar que a diferença de disponibilidade de $\mathrm{N}$ é temporária, ocorrendo no período imediatamente posterior ao manejo que, neste estudo, coincidiu com o florescimento da videira. De outro lado, normalmente, as folhas coletadas no pleno florescimento são mais sensíveis em detectar a alteração na disponibilidade de $\mathrm{N}$ à videira, comparativamente a outras épocas de coleta de folhas, entre elas a mudança da cor das bagas (BRUNETTO et al., 2008).

$\mathrm{O}$ teor de $\mathrm{P}$ nas folhas coletadas na mudança da cor das bagas, nas duas safras, foi menor nos tratamentos com as plantas de cobertura do solo, comparativamente ao tratamento-testemunha (Tabela 1). Na safra de 2010/2011, observou-se menor teor de P nas folhas coletadas na mudança da cor das bagas, nos tratamentos com espécies anuais, comparativamente ao tratamento com espécie perene. $\mathrm{O}$ teor de $\mathrm{K}$ nas folhas coletadas na mudança de cor das bagas, na safra de 2009/2010, foi menor nas videiras consorciadas com as sucessões de espécies anuais do que no tratamento-testemunha (Tabela 1). $\mathrm{O}$ menor teor de $\mathrm{P}$ e $\mathrm{K}$ nas folhas de videiras cultivadas com espécies de plantas de cobertura, como as anuais, pode ser atribuído provavelmente à maior absorção e acúmulo dos dois nutrientes no tecido destas plantas de cobertura, o que diminui a 
disponibilidade no solo para a videira (CELETTE et al., 2009; BRUNETTO et al., 2011). O manejo das plantas de cobertura, com roçada e transferência dos resíduos culturais da linha para as entrelinhas das videiras, não influenciou nos teores de $\mathrm{P}$ e $\mathrm{K}$ nas folhas.

$\mathrm{O}$ teor de $\mathrm{Ca}$ nas folhas coletadas no pleno florescimento e na mudança da cor das bagas, na safra de 2009/2010, foi menor quando consorciada com a espécie perene de planta de cobertura do que com as sucessões de espécies anuais e também do que no tratamento- testemunha (Tabela 1). Já na safra de 2010/2011, os teores de Ca observados nas folhas coletadas na mudança da cor das bagas reforçam o ocorrido na safra anterior. $\mathrm{O}$ teor de Mg, na safra de 2010/2011, nas folhas completas coletadas no pleno florescimento, foi maior nas plantas consorciadas com sucessões de plantas de cobertura anuais, comparativamente àquelas com a planta de cobertura perene e no tratamentotestemunha (Tabela 1). O menor teor total de $\mathrm{Ca}$ e $\mathrm{Mg}$ nas folhas das videiras consorciadas com a planta perene concorda, especialmente, com os teores de $\mathrm{N}$ e $\mathrm{K}$ nas folhas e reforça a possibilidade de que o $\mathrm{Ca}$ e o $\mathrm{Mg}$ se aproximaram das raízes, provavelmente em maior quantidade pelo fluxo de massa, sendo absorvidos pelas raízes e acumulados na parte aérea, uma vez que, comparativamente às espécies anuais, produziram maior quantidade de matéria seca e, provavelmente, raízes, o que implica maior fluxo transpiratório (CELETTE et al., 2009).

\section{Vigor das videiras}

Na safra de 2009/2010, o Índice Ravaz da videira não foi influenciado pelo consócio com as plantas de cobertura do solo (Tabela 2). Porém, na safra de 2010/2011, as sucessões de espécies de plantas anuais diminuíram os valores do Índice de Ravaz, comparativamente ao observado nas videiras do tratamento-testemunha ou consorciadas com a espécie perene. O Índice de Ravaz indica o equilíbrio entre a produção e o vigor das videiras e, de acordo com Kliewer e Dokoozlian (2005), deve situar-se entre 4 e 10, embora valores acima de 7 indicam risco de esgotamento das reservas da planta, como os carboidratos e os nutrientes, devido ao excesso de produção de uva. Já os valores menores que 4 caracterizam o excesso de vigor nas videiras e/ ou a baixa produção de uva. Assim, os resultados obtidos evidenciam que as videiras consorciadas com a espécie perene apresentaram menor vigor. Os valores do Índice de Ravaz, na safra de 2009/2010, observados nas videiras em todos os tratamentos, foram menores que 4, por causa da maior produção de matéria seca dos ramos podados (Tabela 2) e menor produção de uva (Tabela 3), caracterizando o excesso de vigor das plantas, o que concorda com o observado por Borghezan et al. (2011) com a cultivar Cabernet Sauvignon, também na região do Planalto Sul Catarinense. Na safra de 2010/2011, o Índice de Ravaz, nas videiras em todos os tratamentos, situou-se entre 4 e 10, decorrente da menor produção de matéria seca dos ramos (Tabela 2) e da maior produção de uva (Tabela 3), o que pode sugerir a ocorrência de consumo das reservas internas das videiras, podendo, inclusive, afetar negativamente a produção de uva nas safras seguintes.

As videiras, consorciadas com as sucessões de espécies anuais de plantas de cobertura, apresentaram maior comprimento de entrenó dos ramos e maior produção de matéria seca, comparativamente às videiras do tratamento-testemunha e aquelas sob consórcio com a espécie perene (Tabela 2). Já as videiras consorciadas com a planta de cobertura perene apresentaram ramos com menor comprimento, comparativamente às do tratamentotestemunha e as consorciadas com as sucessões de espécies anuais. Os menores comprimentos de ramos e de seus entrenós, nas videiras consorciadas com a espécie perene de planta de cobertura, mostram coerência com os menores teores de nutrientes nas folhas destas videiras, destacando-se $\mathrm{N}, \mathrm{K}, \mathrm{Ca}$ e Mg (Tabela 1), e novamente reforçam a possibilidade de a espécie perene, no caso a festuca, competir significativamente por água e nutrientes do solo com as videiras. Resultados semelhantes foram encontrados por Wheeler et al. (2005), em videiras consorciadas com a chicória, que também apresentaram menor vigor, o que foi atribuído à menor disponibilidade de água e nutrientes no solo, causado, primeiro, pelo hábito perene da planta de cobertura, mas especialmente ao grande volume de solo explorado pelas raízes daquela espécie de planta de cobertura, que possibilita maior absorção de água e nutrientes.

Com base nos resultados de Índice de Ravaz, matéria seca dos ramos podados e comprimento dos ramos e de seus entrenós,verificou-se que o cultivo da festuca, na linha e na entrelinha das videiras, pode provocar a diminuição do vigor da videira, comparativamente aos tratamentos com sucessão de espécies anuais de planta de cobertura, o que concorda com os resultados de Celette et al. (2005),no Sul da França, e de Afonso et al. (2003), em Portugal. Tal resultado pode ser desejável, especialmente em solos com alto teor de matéria orgânica, como o solo do presente trabalho $(81 \mathrm{~g}$ 
$\mathrm{kg}^{-1}$ ), o que lhe confere alta disponibilidade de $\mathrm{N}$, visto que, em videiras menos vigorosas, os raios solares podem incidir com maior facilidade no interior do dossel vegetativo, incrementando, por exemplo, o teor de sólidos solúveis totais nas bagas, mas também o de antocianinas (BRUNETTO et al., 2008) o que, por consequência, pode gerar vinhos de melhor qualidade.

\section{Produção de uva e seus componentes}

A produção de uva por planta e de seus componentes, na safra de 2009/2010, não foi afetada pelos tratamentos com sucessão de espécies anuais e perenes (Tabela 3). No entanto, na safra de 2010/2011, as sucessões de espécies anuais de plantas de cobertura promoveram o aumento da produção de uva por planta em 20 e $35 \%$, em relação àquelas cultivadas no tratamento-testemunha e com a espécie perene, respectivamente. Isso aconteceu porque as videiras cultivadas com a sucessão de espécies anuais apresentaram um número maior de cachos por planta e também cachos com maior largura. Já o manejo das plantas de cobertura através da roçada e a transferência do resíduo cultural da linha para a entrelinha das videiras não afetou a produção de uva por planta, nem tampouco seus componentes.

A maior produção de uvas nas videiras consorciadas com a sucessão de espécies de plantas anuais, na segunda safra, pode ser atribuída ao maior vigor da videira proporcionado por essas plantas (Tabela 2). A maior produção de uva em videiras mais vigorosas não é regra, mas já foi verificada por outros autores (PAULETTO et al., 2001; RUIZCOLMENERO et al., 2011). Por outro lado, nas videiras consorciadas com a espécie perene de planta de cobertura festuca, foi observada a menor produção de uva por planta, consequência, especialmente, dos menores valores de massa de cacho e massa de 100 bagas, comparativamente àquelas consorciadas com as sucessões de plantas de cobertura anuais ou no tratamento-testemunha (Tabela 3). Esses resultados concordam com os menores teores totais de nutrientes nas folhas, especialmente quando coletadas no pleno florescimento (Tabela 1), e também com o menor vigor das videiras consorciadas com a espécie perene de planta de cobertura (Tabela 2). Além disso, estes resultados podem ser explicados pela maior produção acumulada de matéria seca da parte aérea da espécie perene ao longo da realização do experimento, que foi de 10,0 $\mathrm{tha}^{-1}$, comparativamente à parte aérea da sucessão de espécies anuais, que foi de $6,1 \mathrm{tha}^{-1}$. A maior produção de matéria seca da espécie perene, provavelmente, demandou mais água e nutrientes do solo, causando a competição com as videiras (LOPES et al., 2011).

Destaca-se que as videiras do tratamentotestemunha, com a presença de plantas espontâneas, temporária na faixa da linha e permanentes na entrelinha, nas duas safras, produziram a mesma quantidade de uva por planta, comparativamente àquelas consorciadas com a espécie de cobertura perene (Tabela 3 ). Isso pode ser atribuído, possivelmente, às reservas internas de nutrientes $\mathrm{e}$ carboidratos encontradas nas videiras do tratamentotestemunha, normalmente localizadas em maior quantidade nas raízes e nos ramos de mais de um ano (BRUNETTO et al., 2006). É oportuno comentar que, na safra de 2010/2011, a produção de uvas, na média dos tratamentos, foi $50 \%$ maior que na safra de 2009/2010. Embora sejam apenas duas safras avaliadas, insuficientes para observar a alternância de produção, é muito provável que isto tenha acontecido, conforme observado por Pauletto et al. (2001), que durante 8 safras, observaram oscilações anuais na produção de uva. 
TABELA 1- Teores de N, P, K, Ca e Mg totais nas folhas de videiras Cabernet Sauvignon cultivadas em consórcio com plantas de cobertura do solo submetidas a dois manejos.

\begin{tabular}{|c|c|c|c|c|c|c|c|c|c|}
\hline Elemento & Safra & \multicolumn{7}{|c|}{ Tratamentos } & $\mathrm{CV} \%$ \\
\hline & & & Folha & oletada & $\begin{array}{l}\text { oleno } \\
\mathrm{g} \mathrm{kg}^{-1}\end{array}$ & escimen & …........... & …....... & \\
\hline \multirow{2}{*}{$\mathrm{N}$} & $09 / 10$ & 30,3 & 28,6 & 26,8 & 30,2 & 26,5 & 28,5 & 27,8 & 7,2 \\
\hline & $10 / 11$ & 22,3 & 27,7 & 25,1 & 25,8 & 26,4 & 23,3 & 21,7 & 5,6 \\
\hline \multirow{2}{*}{$\mathrm{P}$} & $09 / 10$ & 4,2 & 2,7 & 3,0 & 3,3 & 3,2 & 2,7 & 2,7 & 12,9 \\
\hline & $10 / 11$ & 2,6 & 2,4 & 2,7 & 2,6 & 2,4 & 2,4 & 2,7 & 14,3 \\
\hline \multirow{2}{*}{$\mathrm{K}$} & $09 / 10$ & 14,4 & 13,8 & 13,7 & 14,8 & 15,4 & 15,1 & 14,8 & 10,5 \\
\hline & $10 / 11$ & 12,2 & 11,7 & 11,7 & 13,3 & 11,8 & 12,7 & 13,0 & 11,8 \\
\hline \multirow{2}{*}{$\mathrm{Ca}$} & $09 / 10$ & 16,6 & 13,5 & 13,9 & 18,7 & 16,6 & 13,4 & 14,1 & 9,1 \\
\hline & $10 / 11$ & 12,4 & 13,3 & 15,0 & 15,1 & 14,3 & 13,8 & 13,5 & 5,3 \\
\hline \multirow{2}{*}{$\mathrm{Mg}$} & $09 / 10$ & 4,0 & 3,7 & 3,8 & 3,9 & 3,9 & 3,9 & 4,3 & 13,4 \\
\hline & $10 / 11$ & 2,2 & 2,7 & 3,3 & 3,0 & 2,8 & 2,5 & 2,6 & 11,4 \\
\hline & & & as cole & las na $\mathrm{m}$ & ça de & das bag & & $\ldots \ldots \ldots$ & $\ldots \ldots$ \\
\hline \multirow{2}{*}{$\mathrm{N}$} & $09 / 10$ & 20,9 & 22,8 & 21,4 & 24,3 & 24,4 & 21,6 & 20,5 & 11,7 \\
\hline & $10 / 11$ & 18,1 & 18,0 & 17,5 & 17,1 & 17,9 & 18,6 & 18,7 & 7,9 \\
\hline \multirow{2}{*}{$\mathrm{P}$} & $09 / 10$ & 3,8 & 2,5 & 2,6 & 2,5 & 3,1 & 2,3 & 2,3 & 14,3 \\
\hline & $10 / 11$ & 3,0 & 2,1 & 2,4 & 2,2 & 2,3 & 2,5 & 2,6 & 10,7 \\
\hline \multirow{2}{*}{$\mathrm{K}$} & $09 / 10$ & 17,9 & 15,8 & 15,2 & 14,9 & 16,8 & 15,7 & 15,9 & 11,1 \\
\hline & $10 / 11$ & 15,9 & 13,4 & 14,2 & 16,4 & 15,2 & 15,8 & 15,3 & 13,0 \\
\hline \multirow{2}{*}{$\mathrm{Ca}$} & $09 / 10$ & 23,1 & 21,1 & 20,2 & 23,3 & 23,7 & 18,2 & 17,4 & 11,7 \\
\hline & $10 / 11$ & 18,8 & 16,0 & 17,7 & 17,5 & 17,4 & 16,1 & 16,8 & 5,6 \\
\hline \multirow{4}{*}{$\mathrm{Mg}$} & $09 / 10$ & 3,4 & 3,4 & 3,3 & 3,3 & 3,9 & 3,6 & 3,6 & 14,7 \\
\hline & $10 / 11$ & 3,4 & 3,4 & 3,7 & 3,3 & 3,2 & 3,1 & 3,1 & 9,8 \\
\hline & \multicolumn{9}{|c|}{ Contrastes } \\
\hline & & Test. $\mathrm{x}$ a & & Test. $\mathrm{x}$ & & Anuais & rene & Sem x c & manejo \\
\hline
\end{tabular}

Folhas coletadas no pleno florescimento.

\begin{tabular}{|c|c|c|c|c|c|}
\hline \multirow{2}{*}{$\mathrm{N}$} & $09 / 10$ & $\mathrm{~ns}$ & ns & ns & $*$ \\
\hline & $10 / 11$ & $-* * *(2)$ & ns & $* * *$ & $*$ \\
\hline \multirow{2}{*}{ P } & $09 / 10$ & $* * *$ & $* * *$ & ns & ns \\
\hline & $10 / 11$ & ns & ns & ns & ns \\
\hline \multirow{2}{*}{ K } & $09 / 10$ & ns & $\mathrm{ns}$ & $\mathrm{ns}$ & ns \\
\hline & $10 / 11$ & ns & ns & ns & ns \\
\hline \multirow{2}{*}{$\mathrm{Ca}$} & $09 / 10$ & ns & $* *$ & $* *$ & ns \\
\hline & $10 / 11$ & $-* * *$ & -* & $*$ & ns \\
\hline \multirow{2}{*}{$\mathrm{Mg}$} & $09 / 10$ & ns & ns & ns & ns \\
\hline & 10/11 & $-* * *$ & $\mathrm{~ns}$ & $* *$ & ns \\
\hline
\end{tabular}

.. Folhas coletadas na mudança de cor das bagas.

$\begin{array}{llllll}\mathrm{N} & 09 / 10 & \mathrm{~ns} & \mathrm{~ns} & \mathrm{~ns} & \mathrm{~ns} \\ & 10 / 11 & \mathrm{~ns} & \mathrm{~ns} & \mathrm{~ns} & \mathrm{~ns} \\ \mathrm{P} & 09 / 10 & * * * & * & \mathrm{~ns} & \mathrm{~ns} \\ & 10 / 11 & * * * & \mathrm{~ns} & -* & \mathrm{~ns} \\ \mathrm{~K} & 09 / 10 & * & \mathrm{~ns} & \mathrm{~ns} & \mathrm{~ns} \\ & 10 / 11 & \mathrm{~ns} & * * & \mathrm{~ns} & \mathrm{~ns} \\ \mathrm{Ca} & 09 / 10 & \mathrm{~ns} & * * * & * * * & \mathrm{~ns} \\ & 10 / 11 & * * & \mathrm{~ns} & \mathrm{~ns} & \mathrm{~ns} \\ \mathrm{Mg} & 09 / 10 & \mathrm{~ns} & \mathrm{~ns} & * \cdots \cdots \cdots \cdots \cdots \cdots\end{array}$

(1)T1: Testemunha; T2: (moha + azevém), roçado; T3: (moha + azevém), roçado com transferência; T4: (trigo-mourisco + aveia-branca), roçado; T5: (trigo-mourisco + aveia-branca), roçado com transferência; T6: (festuca), roçada; T7: (festuca), roçada com transferência do resíduo cultural para a entrelinha da videira. *, $* *, * * *$ Houve diferença significativa entre os tratamentos que formam o contraste a $(\mathrm{P}<0,05)(\mathrm{P}<0,01)(\mathrm{P}<0,001)$, respectivamente. $\mathbf{n s}$ contrastes não significativos. ${ }^{(2)} \mathrm{O}$ sinal negativo $(-)$ antes do asterisco $(*)$ indica que o grupo de tratamentos à direita, que contrasta com o grupo anterior para formar o contraste, apresenta valores maiores da variável em questão. 
TABELA 2- Índice de Ravaz, matéria seca de ramos por planta, comprimento de ramos e de seus entrenós em videiras Cabernet Sauvignon cultivadas em consórcio com plantas de cobertura do solo e submetidas a dois tipos de manejos.

\begin{tabular}{|c|c|c|c|c|c|c|c|c|c|}
\hline \multirow{2}{*}{ Variável } & \multirow{2}{*}{ Safra } & \multicolumn{7}{|c|}{ Tratamentos } & \multirow{2}{*}{$\mathrm{CV} \%$} \\
\hline & & $\mathrm{T}^{(1)}$ & T2 & $\mathrm{T} 3$ & T4 & T5 & T6 & $\mathrm{T} 7$ & \\
\hline \multirow{2}{*}{ Índice Ravaz } & $09 / 10$ & 2,07 & 2,25 & 2,07 & 2,20 & 2,08 & 2,36 & 2,28 & 10,1 \\
\hline & $10 / 11$ & 6,78 & 5,69 & 5,49 & 6,16 & 5,69 & 6,32 & 6,56 & 9,4 \\
\hline \multirow{2}{*}{$\begin{array}{l}\text { Matéria seca de } \\
\text { ramos }(\mathrm{kg})\end{array}$} & $09 / 10$ & 1,21 & 1,39 & 1,40 & 1,31 & 1,37 & 1,20 & 1,30 & 8,5 \\
\hline & $10 / 11$ & 0,51 & 0,72 & 0,76 & 0,69 & 0,73 & 0,43 & 0,51 & 12,7 \\
\hline $\begin{array}{l}\text { Comprimento } \\
\text { entrenós }(\mathrm{cm})\end{array}$ & $10 / 11$ & 6,17 & 7,02 & 7,00 & 6,89 & 6,93 & 6,07 & 6,07 & 6,3 \\
\hline \multirow[t]{3}{*}{$\begin{array}{l}\text { Comprimento } \\
\text { do ramo }(\mathrm{cm})\end{array}$} & $10 / 11$ & 123 & 128 & 132 & 128 & 129 & 104 & 114 & 5,8 \\
\hline & \multicolumn{9}{|c|}{ Contrastes entre tratamentos } \\
\hline & & \multicolumn{2}{|c|}{ Test. $\mathrm{x}$ anuais } & \multicolumn{2}{|c|}{ Test. $\mathrm{x}$ perene } & \multicolumn{2}{|c|}{ Anuais x perene } & \multicolumn{2}{|c|}{ Sem $x$ com manejo } \\
\hline \multirow{2}{*}{ Índice Ravaz } & $09 / 10$ & \multicolumn{2}{|c|}{ ns } & \multicolumn{2}{|c|}{ ns } & \multicolumn{2}{|c|}{ ns } & \multicolumn{2}{|c|}{ ns } \\
\hline & $10 / 11$ & \multicolumn{2}{|c|}{$* *$} & \multicolumn{2}{|c|}{ ns } & \multicolumn{2}{|c|}{$-*$} & \multicolumn{2}{|c|}{ ns } \\
\hline \multirow{2}{*}{$\begin{array}{c}\text { Matéria seca } \\
\text { de ramos }\end{array}$} & $09 / 10$ & \multicolumn{2}{|c|}{$-*(2)$} & \multicolumn{2}{|c|}{$\mathrm{ns}$} & \multicolumn{2}{|c|}{$*$} & \multicolumn{2}{|c|}{ ns } \\
\hline & $10 / 11$ & \multicolumn{2}{|c|}{$-* * *$} & \multicolumn{2}{|c|}{ ns } & \multicolumn{2}{|c|}{$* * *$} & \multicolumn{2}{|c|}{ ns } \\
\hline $\begin{array}{l}\text { Comprimento } \\
\text { entrenós }\end{array}$ & $10 / 11$ & \multicolumn{2}{|c|}{$-* *$} & \multicolumn{2}{|c|}{ ns } & \multicolumn{2}{|c|}{$* * *$} & \multicolumn{2}{|c|}{ ns } \\
\hline Comprimento do ramo & $10 / 11$ & \multicolumn{2}{|c|}{ ns } & \multicolumn{2}{|c|}{ ** } & & & & \\
\hline
\end{tabular}

(1) T1: Testemunha; T2: (moha + azevém), roçado; T3: (moha + azevém), roçado com transferência; T4: (trigo-mourisco + aveia-branca), roçado; T5: (trigo-mourisco + aveia-branca), roçado com transferência; T6: (festuca), roçada; T7: (festuca), roçada com transferência do resíduo cultural para a entrelinha da videira. *,**,*** Houve diferença significativa entre os tratamentos que formam o contraste a $(\mathrm{P}<0,05)(\mathrm{P}<0,01)(\mathrm{P}<0,001)$, respectivamente. ns contrastes não significativos. ${ }^{(2)} \mathrm{O}$ sinal negativo (-) antes do asterisco $\left({ }^{*}\right)$ indica que o grupo de tratamentos à direita, que contrasta com o grupo anterior para formar o contraste, apresenta valores maiores da variável em questão. 
TABELA 3- Produção e número de cachos por planta, massa média de cacho e de 100 bagas, comprimento e largura do cacho, de videiras Cabernet Sauvignon cultivadas em consórcio com plantas de cobertura do solo e submetidas a dois tipos de manejos.

\begin{tabular}{cccccccccc}
\hline \multirow{2}{*}{ Variável } & \multirow{2}{*}{ Safra } & \multicolumn{7}{c}{ Tratamentos } & \multirow{2}{*}{ CV \% } \\
\cline { 3 - 7 } & & T1 $1^{(1)}$ & $\mathrm{T} 2$ & $\mathrm{~T} 3$ & $\mathrm{~T} 4$ & $\mathrm{~T} 5$ & $\mathrm{~T} 6$ & $\mathrm{~T} 7$ & \\
\hline Produção por & $09 / 10$ & 2,14 & 2,50 & 2,38 & 2,45 & 2,29 & 2,50 & 2,59 & 13,6 \\
planta (kg) & $10 / 11$ & 3,34 & 3,92 & 4,05 & 4,12 & 4,04 & 2,69 & 3,30 & 11,7 \\
Cachos por & $09 / 10$ & 22,6 & 23,2 & 23,5 & 21,6 & 22,8 & 25,4 & 23,5 & 11,1 \\
planta & $10 / 11$ & 24,5 & 26,8 & 29,1 & 28,6 & 28,6 & 26,0 & 28,1 & 9,0 \\
Massade & $09 / 10$ & 108,0 & 109,6 & 116,1 & 124,0 & 114,9 & 109,6 & 114,8 & 9,8 \\
cacho (g) & $10 / 11$ & 114,8 & 121,0 & 125,1 & 132,8 & 122,5 & 103,3 & 114,3 & 11,0 \\
Massa 100 & $09 / 10$ & 145,8 & 138,7 & 145,7 & 143,6 & 143,5 & 141,2 & 143,3 & 4,7 \\
bagas (g) & $10 / 11$ & 142,5 & 150,4 & 140,1 & 145,0 & 139,4 & 108,7 & 130,2 & 8,1 \\
Comprimento & $09 / 10$ & 13,26 & 13,36 & 13,39 & 13,62 & 13,82 & 14,02 & 13,69 & 5,5 \\
cacho (cm) & $10 / 11$ & 13,73 & 14,30 & 13,30 & 14,25 & 13,03 & 13,51 & 13,68 & 4,4 \\
Largura & $09 / 10$ & 7,25 & 7,04 & 7,57 & 7,27 & 7,40 & 7,41 & 7,50 & 5,2 \\
cacho (cm) & $10 / 11$ & 7,03 & 8,06 & 7,95 & 7,43 & 7,90 & 7,56 & 7,03 & 8,8 \\
\hline
\end{tabular}

Contrastes entre tratamentos

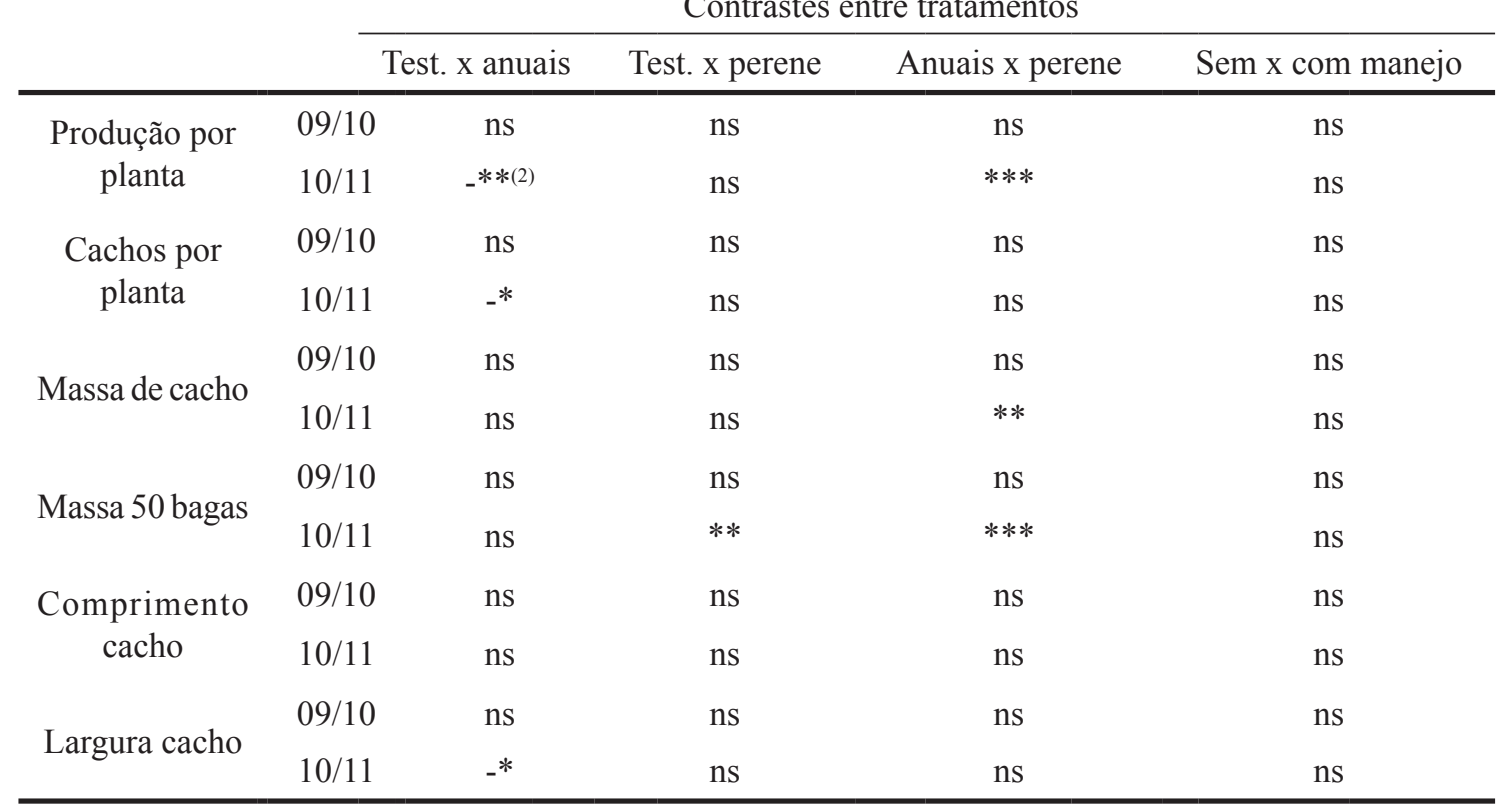

(1) T1: Testemunha; T2: (moha + azevém), roçado; T3: (moha + azevém), roçado com transferência; T4: (trigo-mourisco + aveia-branca), roçado; T5: (trigo- mourisco + aveia-branca), roçado com transferência; T6: (festuca), roçada; T7: (festuca), roçada com transferência do resíduo cultural para a entrelinha da videira. *, $* *, * * *$ Houve diferença significativa entre os tratamentos que formam o contraste a $(\mathrm{P}<0,05)(\mathrm{P}<0,01)(\mathrm{P}<0,001)$, respectivamente. ns contrastes não significativos. ${ }^{(2)} \mathrm{O}$ sinal negativo $(-)$ antes do asterisco $(*)$ indica que o grupo de tratamentos à direita, que contrasta com o grupo anterior para formar o contraste, apresenta valores maiores da variável em questão. 


\section{CONCLUSÕES}

1- As videiras consorciadas com as sucessões de espécies anuais de plantas de cobertura, aveiabranca trigo-mourisco e azevém-moha, apresentam maiores vigor, rendimento de uva e teor de nitrogênio total nas folhas coletadas no pleno florescimento.

2- A transferência dos resíduos culturais das plantas de cobertura da linha de plantio das videiras para a entrelinha, não afeta o vigor das plantas, nem a produção de uva, mas diminui o teor de nitrogênio total nas folhas coletadas no pleno florescimento.

3-A planta de cobertura festuca, cultivada em consórcio com a videira, apresenta alta capacidade de competição e pode ser uma alternativa para diminuir $o$ vigor dessa frutífera.

\section{AGRADECIMENTOS}

Os autores agradecem à Vinícola Suzin, por disponibilizar os vinhedos comerciais para a instalação do experimento; À Fundação de Amparo à Pesquisa e Inovação do Estado de Santa Catarina (FAPESC), pelo auxílio financeiro; À Coordenação de Aperfeiçoamento de Pessoal de Nível Superior (CAPES), pela concessão de bolsa de Doutorado concedida ao primeiro autor.

\section{REFERÊNCIAS}

AFONSO, J.M.; MONTEIRO, A.; LOPES, C.M.; LOURENÇO, J. Enrelvamento do solo em vinha na região dos Vinhos Verdes. Três anos de estudo na casta 'Alvarinho'. Ciência e Técnica Vitivinícola, Dois Portos, v.18, n.2, p.47-63, 2003.

BORGHEZAN, M.; GAVIOLI, O.; PIT, F.A.; SILVA, A.L.da. Comportamento vegetativo e produtivo da videira e composição da uva em São Joaquim, Santa Catarina. Pesquisa Agropecuária Brasileira, Brasília, v.46, n.4, p.398-405, 2011.

BRUNETTO, G.; BONGIORNO, C.L.; MATTIAS, J.L.; DEON, M.; MELO, G.W.; KAMINSKI, J.; CERETTA, C.A. Produção, composição da uva e teores de nitrogênio na folha e no pecíolo em videiras submetidas à adubação nitrogenada. Ciência Rural, Santa Maria, v.38, n.9, p.2.622-2.625, 2008.
BRUNETTO, G.; CERETTA, C.A.; KAMINSKI, J.; MELO, G.W.B.; LOURENZI, C.R.; FURLANETTO, V.; MORAES, A. Aplicação de nitrogênio em videiras na Campanha Gaúcha: Produtividade e características químicas do mosto da uva. Ciência Rural, Santa Maria, v.37, n.2, p.389-393, 2007.

BRUNETTO, G.; KAMINSKI, J.; MELO, G.W.B.; BRUNING, F.S.; MALLMANN, F. Destino do nitrogênio em videiras 'Chardonnay' e 'Riesilng Renano' quando aplicado no inchamento das gemas. Revista Brasileira de Fruticultura, Jaboticabal, v.28, n.3, p.497-500, 2006.

BRUNETTO, G. ; TRENTIN, G.; CERETTA, C.A. ; GIROTTO, E.; LORENSINI, F.; MIOTTO, A.; MOSER, G; MELO, G.W.B. Use of the SPAD-502 in estimating nitrogen content in leaves and grape yield in grapevines in soils with different texture. American Journal of Plant Sciences, Irvine, v.3, p.1.546-1.561, 2012.

BRUNETTO, G.; VENTURA, M.; SCANDELLARI, F.; CERETTA, C.A.; KAMINSKI, J.; MELO, G.W.; TAGLIAVINI, M. Nutrient release during the decomposition of mowed perennial ryegrass and white clover and its contribution to nitrogen nutrition of grapevine. Nutrient Cycling in Agroecosystems, New York, v.90, n.3, p.299-308, 2011.

CELETTE, F.; Findeling, A.; GARY, C. Competition for nitrogen in an unfertilized intercropping system: The case of an association of grapevine and grass cover in a Mediterranean climate. European Journal of Agronomy, Amsterdam, v.30, n.1, p.41-51, 2009.

CELETTE, F.; WERY, J.; CHANTELOT, E.; CELLETE, J.; GARY, C. Belowground interactions in a vine Vitisvinifera L.-tall fescue Festuca arundinacea Shreb. Intercropping system: water relations and growth. Plant and Soil, Dordrecht, v.276, n.1-2, p.205-217, 2005.

COLUGNATI, G.; CRESPAN, G.; PICCO, D.; BREGANT, F.; TONETTI, I.; GALLAS, A.; ALTISSIMO, A. Comportamento di diverse essenze per l'inerbimento del vigneto. L'informatore agrario, Verona, n.13, p.55-59, 2003.

CQFS - Comissão de Química e Fertilidade do Solo. Manual de adubação e calagem para os Estados do Rio Grande do Sul e de Santa Catarina. 10.ed. Porto Alegre: SBCS, 2004. 400p. 
CUS, F. The effect of different scion/rootstock combinations on yield properties of cv. 'Cabernet Sauvignon'. Acta Agriculturae Slovenica, Slovenia, v. 83, p. $63-71,2004$.

DUCHÊNE, E.; SCHNEIDER, C.; GAUDILLÈRE, J.P. Effects of nitrogen nutrition timing on fruit set of grapevine cv. Grenache. Vitis, Landau, v.40, n.1, p.45-46, 2001.

EISSENSTAT, D.M. Dinamica di crescita delle radici nelle colture da frutto. Italus Hortus, Firenze, v.14, n.1, p.1-8, 2007.

EMBRAPA-CNPS. Manual de métodos de análise de solos. Rio de Janeiro, 1997. 212p.

KELLER, M.; POOL, R.M.; HENICK-KLING, T. Excessive nitrogen supply and shoot trimming can impair colour development in Pinot Noir grapes and wine. Australian Journal of Grape and Wine Research, Adelaide, v.5, n.2, p.45-55, 1999.

KLIEWER, W.M.; DOKOOZLIAN, N.K. Leaf area/ crop weight ratios of grapevines: influence on fruit composition and wine quality. American Journal of Enology and Viticulture, Davis, v.56, n.2, p.170$181,2005$.

LOPES, C.M.; MONTEIRO, A.; MACHADO, J.P. Cover cropping in a sloping non-irrigated vineyard: ii - Effects on vegetative growth, yield, berry and wine quality of 'Cabernet Sauvignon' grapevines. Ciência e Técnica Vitivinícola, Dois Portos, v.23, n.1, p.3743, 2008 .

LOPES, C.M.; SANTOS, T.P.; MONTEIRO, A.; RODRIGUES, M. L.; COSTA, J.M.; CHAVES, M.M. Combining cover cropping with deficit irrigation in a Mediterranean low vigor vineyard. Scientia Horticulturae, Amsterdam, v.129, n.4, p.603-612, 2011.

MAFRA, M.S.H.; CASSOL, P.C.; MIQUELLUTI, D.J.; ERNANI, P.R.; GATIBONI, L.C.; FERREIRA, E.Z.; BARROS, M.;ZALAMENA, J.; GROHSKOPF, M.A. Atributos químicos do solo e estado nutricional de videira Cabernet Sauvignon (Vitis vinifera L.) na Serra Catarinense. Revista de Ciências Agroveterinárias, Lages, v.10, n.1, p.44-53, 2011.
PAULETTO, D.; MOURÃO FILHO, F.A.A.; KLUGE, R.A.; SCARPARE FILHO, J.A. Produção e vigor da videira 'Niágara Rosada' relacionados com o porta-enxerto. Pesquisa Agropecuária Brasileira, Brasília, v.36, n.1, p.115-121, 2001.

RUIZ-COLMENERO, M.; BIENES, R.; MARQUES, M.J. Soil and water conservation dilemmas associated with the use of green cover in steep vineyards. Soil \& Tillage Research, Amsterdam, v.117, p.211-223, 2011.

SCIENZA, A.; SICHER, L.; VENTURELLI, M. B.; MAGGIORE, T.; PISANI, L.; CORINO, L. L'inerbimento in viticoltura. L'informatore agrario, Verona, n.21, p.29-49, 1988.

SOARES, J.M.; NASCIMENTO, T. Distribuição do sistema radicular da videira em Vertissolo sob irrigação localizada. Revista Brasileira de Engenharia Agrícola e Ambiental, Campina Grande, v.2, n.2, p.142-147, 1998.

TEDESCO, M.J.; GIANELLO, C.; BISSANI, C.; BOHNEN, H. Análise de solo, plantas e outros materiais. 2.ed. Porto Alegre, Universidade Federal do Rio Grande do Sul, 1995. 174 p. (Boletim Técnico, $5)$.

VALENTI, L.; MAGGIORE, T.; SCIENZA, A. Tecniche di gestione del suolo in viticoltura. L'informatore agrario, Verona, n.38, p.35-37, 1999.

WHEELER, S.J.; BLACK, A.S.; PICKERING, G. J. Vineyard floor management improves wine quality in highly vigorous Vitis vinifera 'Cabernet Sauvignon' in New Zealand. New Zealand Journal of Crop and Horticultural Science, Wellington, v.33, n.3, p.317-328, 2005.

ZALAMENA, J. Plantas de cobertura na redução do vigor da videira em solo com alto teor de matéria orgânica. 2012. 73f. Tese (Doutorado em Manejo do Solo) - Universidade do Estado de Santa Catarina, Lages, 2012.

ZALAMENA, J.; CASSOL, P.C.; BRUNETTO, G.; PANISSON, J.; FILHO, J.L.M.; SCHLEMPER, C. Produtividade e composição de uva e de vinho de videiras consorciadas com plantas de cobertura. Pesquisa Agropecuária Brasileira, Brasília, v.48, n.2, p.182-189, 2013. 